\title{
Dental Caries Experience among School-going Children Based on Diet, Physical Activity, and Adiposity in South Bengaluru: A Questionnaire Study
}

\author{
BS Shakuntala ${ }^{1}$, P Sirisha $^{2}$, Manasi P Kulkarni ${ }^{3}$
}

\begin{abstract}
Introduction: Dental caries remains to be a significant health concern since childhood. Caries prevalence in developing nations has increased due to an array of factors such as diet, low socioeconomic status, exposure to fluorides, ethnicity, age, the limited access to oral health services, and other lifestyle factors. Childhood obesity and physical activity are interrelated and have known to influence dental caries prevalence.

Aim: The aim of this study is to evaluate the role of diet, physical activity, and adiposity in children from schools of two different lifestyles and its influence on dental caries.

Materials and methods: A cross-sectional study was performed by recruiting 300 children in the age group of 6-10 years. The schools were categorized into two groups: group I-day scholar schools and group II—residential schools. The data regarding the diet, physical activity, and adiposity were collected using a questionnaire given to the child and the parent. Anthropometric measurements of all the children were recorded. Results: The consumption of junk and access to gadgets was greater in group I children compared to that in group II and the amount of physical activity was greater in residential schools. The group I school children were known to be more obese compared to the children from group II and a statistical significance was seen with the caries experience among the two groups.

Conclusion: Diet, physical activity, and adiposity could influence the dental caries experience among school-going children.

Keywords: Adiposity, Diet, Dental caries, Physical activity.

Journal of Health Sciences \& Research (2019): 10.5005/jp-journals-10042-1075
\end{abstract}

\section{INTRODUCTION}

Dental caries is stated to be the most prevalent chronic disease of childhood, affecting more than half of the children aged 5-17 years. ${ }^{1}$ It is well known to be a diet-mediated disease. There is extensive scientific evidence that free sugars are the primary necessary factor in the development of dental caries. Several recent studies have suggested a strong correlation between caries raise in caries incidence and the consumption of sweets. ${ }^{2}$ Though diet cannot be the only causative factor, other factors are also contributors to the current caries levels.

Recently, caries prevalence has increased in developing nations due to an array of factors, such as intake of sugary foods, low socioeconomic status, the limited access to oral health services, and other lifestyle factors. Over the past few years, dental caries is been closely associated with adiposity. ${ }^{1}$ Obesity among youth is a serious problem confronting families, communities, health care providers, and public health authorities. Over the past 3 decades, the prevalence of obesity has more than tripled for youth aged 6-11 years. ${ }^{3}$

Changes in lifestyle and diet since the mid-1990s due to increased affluence and access to high-caloric carbohydrate-rich foods and drinks may help account for the rising prevalence in dental caries and obesity. Given the strong evidence supporting the association of dental caries with irregular dietary patterns and quality and the fact that abnormal dietary intake has been linked to the development of obesity at a young age, a link between dental caries and body weight is biologically plausible., ${ }^{4,5}$ When children watch a lot of TV, they tend to snack more frequently, particularly on foods that are high in fat and/or sugar. ${ }^{6}$ This not only increases their overall caloric intake, which can lead to obesity, but it also increases
${ }^{1-3}$ Department of Pedodontics and Preventive Dentistry, RajaRajeswari Dental College and Hospital, Bengaluru, Karnataka, India

Corresponding Author: P Sirisha, Department of Pedodontics and Preventive Dentistry, RajaRajeswari Dental College and Hospital, Bengaluru, Karnataka, India, Phone: +91 9620236930, e-mail: siri. pandravada1@gmail.com

How to cite this article: Shakuntala BS, Sirisha P, Kulkarni MP. Dental Caries Experience among School-going Children Based on Diet, Physical Activity, and Adiposity in South Bengaluru: A Questionnaire Study. J Health Sci Res 2019;10(1):1-6.

Source of support: Nil

Conflict of interest: None

their risk of developing tooth decay because the amount of time food is in contact with the teeth increases. ${ }^{7}$ The increased frequency of usage of electronic gadgets such as mobile phones, laptops, and watching television has become a major mode of entertainment among young children decreasing the physical activity and outdoor games which is an additional factor for obesity among them.

The objectives of this study were to compare diet, physical activity, and body weight in schools following different lifestyles one being residential and the other being a day scholar school and relate its influence with dental caries.

\section{Materials and Methods}

A cross-sectional study was performed by recruiting 300 children in the age group of 6-10 years from a few schools at close quarters to the dental college and their willingness to participate. The schools were categorized into two groups: group I-day scholar schools and 
group II-residential schools. Of which, 150 children were from day scholar school and 150 from the residential school. Permission to conduct the study was obtained from the Principals of the schools. Ethical clearance was obtained from the institution prior to the study. An official consent from the parents was obtained.

Children with special needs, mentally, and physically challenged were excluded from the study.

\section{Data Collection}

The data were collected using questionnaires that were distributed to the children of both the categories and a copy of the questionnaire was sent home along with the child for the parents or caregivers to complete. The questionnaire was validated by conducting a pilot study.

\section{Assessment}

All children were asked to complete the questionnaire and physical measurements were taken by a single dentist.

\section{Child Questionnaire}

The questionnaire composed of 23 closed-ended questions. In the questionnaire, diet, physical activity, and dental experience of the child were recorded.

First, the demographic data regarding age, sex of the child, and number of siblings the child had were recorded.

Diet was assessed by using questions regarding the number of snacks breaks the child had during the school hours, and the type of food taken by the child during the break if it was biscuits and chips or sweets, cakes, or fruits and salads. The type of food taken during the lunch hour like rice, chapatti, and vegetables or processed food items was recorded. Questions on the frequency of intake of junk food, sweets, and candies as well as consumption of soft drinks during and after the school hours were also asked. Questions on the habit of snacking in front of the television were also included.

Physical activity was assessed using questions regarding the means of transport to school and distance from the residence to know if the child walked to the school or used other means of transport to commute. Questions regarding the time spent on various activities like study, play, co-curricular activities, on electronic gadgets such as laptops, smartphones, and hours of watching television and the time the child went to bed were included in the questionnaire.

The dental experience of the child was recorded by using questions regarding the number of visits to the dentist in past, food lodgment in teeth, presence of black discoloration in teeth, experience of toothache or sensitivity, and its frequency and if it leads to absenteeism to school was recorded.

The questionnaires were completed separately by the children at the school under the dentist's supervision and by the caregivers or parents at home. The questionnaire from the parents was collected from the children the next day.

\section{Anthropometry}

Child height, weight, waist, and hip circumference were measured using a standardized protocol. The height was measured without shoes and the weight was calculated in light clothes using a portable scale. The waist circumference was measured at the smallest diameter between the coastal margin and the iliac crest, at the end of normal expiration using a non-stretchable tape. Body mass index (BMI) was calculated by dividing weight in kilograms by height in meters squared.

\section{Parent Questionnaire}

The parent questionnaire was the same as that given to the children. Questions such as the household income and educational level of the parents were recorded in the questionnaire given to parents to relate the influence of socioeconomic status and educational level to oral health status and awareness.

\section{Statistical Analysis}

Statistical Package for Social Sciences [SPSS] for Windows Version 22.0 was used. Descriptive analysis of all the explanatory and outcome parameters was done using mean and standard deviation for quantitative variables, frequency, and proportions for categorical variables. The independent Student $t$ test was used to compare the mean age and BMI levels between the two groups. The Chi-square test was used to compare the difference in the distribution of responses between the residential and day scholar school children as well as parents. The level of significance was set at $p<0.05$

\section{Results}

A total of 300 children, 149 girls and 152 boys, in age ranging from 6 to 10 years were included in the study as shown in Table 1. One hundred fifty children were from the day scholar schools and 150 from the residential schools.

In a day scholar school, almost $70 \%$ of children traveled by a school bus as the distance from their residence to the school was $>2-3 \mathrm{~km}$.

In residential schools, most children preferred to walk to the school as the distance ranged $1 \mathrm{~km}$ or less and only $30 \%$ of children traveled by a school bus wherein the distance from the hostel to school was $>2-3 \mathrm{~km}$.

The data in Table 2 summarize the comparison of various study characteristics among the children from both the schools.

A majority of the schools from both the categories had only one snack break during the school hours. The children commuting from their home usually preferred to have biscuits and chips during the breaks followed by sweets, cakes, and other junk. Almost $50 \%$ of children reported to have junk food and soft drinks at least once a day or more than that.

In the hostel premises, the preferred food for the snack break was milk along with biscuits which was constant throughout the year, although almost $40 \%$ of children have reported to have junk food at least once a day but consumption of soft drinks was restricted to once a month or lesser.

Children from both the categories of schools had rice and vegetable or chapatti and curry for lunch and only around $20 \%$ of day school children carried junk food for lunch occasionally.

About $70-80 \%$ of schools reported to have a physical education class for 2 hours or more per week during the school hours. About $45 \%$ of children have reported to play indoor games such as chess, carom, or others and $55 \%$ of children have reported to play games such as cricket, volleyball, cycling, or others in a day scholar school either during the school hours or after. Apart from physical education hour, $60 \%$ of children from a day scholar school played at least for around 20 minutes during the free time in the school.

The residential schools had regular physical education classes for more than 2 hours per week. About $60-70 \%$ of children reported to play sports such as cricket, volleyball cycling, or others and very few children reported to play indoor games such as chess, carom, or others choice during the school hours. Residential school children 
Table 1: Characteristics of schoolchildren between day scholar and residential school

\begin{tabular}{|c|c|c|c|c|c|c|}
\hline \multirow[b]{2}{*}{ Variables } & \multirow[b]{2}{*}{ Categories } & \multicolumn{2}{|c|}{ Day scholar $(n=150)$} & \multicolumn{2}{|c|}{ Residential school $(n=150)$} & \multirow[b]{2}{*}{$p$ value } \\
\hline & & $n$ & $\%$ & $n$ & $\%$ & \\
\hline \multirow[t]{3}{*}{ Sex } & Males & 74 & 49.3 & 87 & 58.0 & 0.13 \\
\hline & Females & 76 & 50.7 & 63 & 42.0 & \\
\hline & & Mean & SD & Mean & SD & \\
\hline \multirow[t]{2}{*}{ Age (in years) } & Mean and SD & 8.2 & 1.5 & 8.4 & 1.4 & 0.17 \\
\hline & Range & $6-10$ & & $6-10$ & & \\
\hline \multirow[t]{3}{*}{ BMI } & Mean and SD & 17.9 & 4.7 & 20.5 & 5.0 & $<0.001^{*}$ \\
\hline & Range & $09-31.1$ & & $10.3-37.6$ & & \\
\hline & & $n$ & $\%$ & $n$ & $\%$ & \\
\hline \multirow[t]{4}{*}{ BMI status } & Underweight & 54 & 36.0 & 97 & 64.7 & $<0.001^{*}$ \\
\hline & Normal & 68 & 45.3 & 39 & 26.0 & \\
\hline & Overweight & 22 & 14.7 & 12 & 8.0 & \\
\hline & Obese & 6 & 4.0 & 2 & 1.3 & \\
\hline
\end{tabular}

*Statistically significant

Table 2: Comparison of study characteristics of schoolchildren between day scholar and residential school using the Chi-square test

\begin{tabular}{|c|c|c|c|c|c|c|c|}
\hline \multirow[b]{2}{*}{ Variables } & \multirow[b]{2}{*}{ Categories } & \multicolumn{2}{|c|}{ Day scholar $(n=150)$} & \multicolumn{2}{|c|}{ Residential school $(n=150)$} & \multirow[b]{2}{*}{$\chi^{2}$ value } & \multirow[b]{2}{*}{$p$ value } \\
\hline & & $n$ & $\%$ & $n$ & $\%$ & & \\
\hline \multirow[t]{4}{*}{ No. of siblings } & No siblings & 14 & 9.3 & 32 & 21.3 & 9.494 & $0.02 *$ \\
\hline & One & 86 & 57.3 & 67 & 44.7 & & \\
\hline & Two & 36 & 24.0 & 38 & 25.3 & & \\
\hline & $>$ Two & 14 & 9.3 & 13 & 8.7 & & \\
\hline \multirow[t]{4}{*}{ Transport } & By walk & 42 & 28.0 & 53 & 35.3 & 4.863 & 0.18 \\
\hline & School bus & 96 & 64.0 & 78 & 52.0 & & \\
\hline & Public transport & 3 & 2.0 & 6 & 4.0 & & \\
\hline & Others & 9 & 6.0 & 13 & 8.7 & & \\
\hline \multirow[t]{4}{*}{ Distance } & $<1 \mathrm{~km}$ & 46 & 30.7 & 32 & 21.3 & 11.837 & $0.008^{*}$ \\
\hline & $2-3 \mathrm{~km}$ & 76 & 50.7 & 71 & 47.3 & & \\
\hline & $3-5 \mathrm{~km}$ & 14 & 9.3 & 12 & 8.0 & & \\
\hline & $>5 \mathrm{~km}$ & 14 & 9.3 & 35 & 23.3 & & \\
\hline \multirow[t]{4}{*}{ Snack breaks } & No snack break & 3 & 2.0 & 6 & 4.0 & 52.468 & $<0.001^{*}$ \\
\hline & 1 break & 124 & 82.7 & 71 & 47.3 & & \\
\hline & 2 breaks & 23 & 15.3 & 41 & 27.3 & & \\
\hline & $>2$ breaks & 0 & 0.0 & 32 & 21.3 & & \\
\hline \multirow[t]{4}{*}{ Snacks } & Fruits and salads & 40 & 26.7 & 64 & 42.7 & 16.928 & $0.001^{*}$ \\
\hline & Biscuit and chips & 87 & 58.0 & 62 & 41.3 & & \\
\hline & Sweet and cakes & 17 & 11.3 & 24 & 16.0 & & \\
\hline & Others & 6 & 4.0 & 0 & 0.0 & & \\
\hline \multirow[t]{4}{*}{ Lunch } & Rice and veg & 77 & 51.3 & 59 & 39.3 & 8.163 & $0.04 *$ \\
\hline & Chapatti and veg & 58 & 38.7 & 82 & 54.7 & & \\
\hline & Biscuit and chips & 7 & 4.7 & 5 & 3.3 & & \\
\hline & Others & 8 & 5.3 & 4 & 2.7 & & \\
\hline \multirow[t]{4}{*}{ PE class/week } & 2 hours & 27 & 18.0 & 41 & 27.3 & 36.888 & $<0.001^{*}$ \\
\hline & $2-3$ hours & 24 & 16.0 & 25 & 16.7 & & \\
\hline & $<2$ hours & 60 & 40.0 & 81 & 54.0 & & \\
\hline & $>3$ hours & 39 & 26.0 & 3 & 2.0 & & \\
\hline \multirow[t]{4}{*}{ Plat at school } & 20 minutes & 17 & 11.3 & 3 & 2.0 & 51.751 & $<0.001^{*}$ \\
\hline & $<20$ minutes & 45 & 30.0 & 67 & 44.7 & & \\
\hline & 20-30 minutes & 55 & 36.7 & 80 & 53.3 & & \\
\hline & No play time & 33 & 22.0 & 0 & 0.0 & & \\
\hline
\end{tabular}


Contd..

\begin{tabular}{|c|c|c|c|c|c|c|c|}
\hline \multirow{2}{*}{ Variables } & \multirow[b]{2}{*}{ Categories } & \multicolumn{2}{|c|}{ Day scholar $(n=150)$} & \multicolumn{2}{|c|}{ Residential school $(n=150)$} & \multirow[b]{2}{*}{$\chi^{2}$ value } & \multirow[b]{2}{*}{ pvalue } \\
\hline & & $n$ & $\%$ & $n$ & $\%$ & & \\
\hline \multirow[t]{4}{*}{ Plat at home } & 30 minutes & 24 & 16.0 & 41 & 27.3 & 13.817 & $0.003^{*}$ \\
\hline & $<30$ minutes & 86 & 57.3 & 82 & 54.7 & & \\
\hline & $1-2$ hours & 31 & 20.7 & 27 & 18.0 & & \\
\hline & $>2$ hours & 9 & 6.0 & 0 & 0.0 & & \\
\hline \multirow[t]{3}{*}{ Regular sports } & Indoor & 80 & 53.3 & 97 & 64.7 & 3.982 & $0.04^{*}$ \\
\hline & Outdoor & 70 & 46.7 & 53 & 35.3 & & \\
\hline & Indoor sports & & & & & & \\
\hline \multirow[t]{9}{*}{ Sports type } & Chess & 8 & 5.3 & 15 & 10.0 & 40.256 & $<0.001^{*}$ \\
\hline & Carom & 20 & 13.3 & 12 & 8.0 & & \\
\hline & Video games & 19 & 12.7 & 41 & 27.3 & & \\
\hline & Others & 33 & 22.0 & 29 & 19.3 & & \\
\hline & Outdoor sports & & & & & & \\
\hline & Cycling & 22 & 14.7 & 9 & 6.0 & & \\
\hline & Cricket & 15 & 10.0 & 32 & 21.3 & & \\
\hline & Volley/foot ball & 18 & 12.0 & 12 & 8.0 & & \\
\hline & Others & 15 & 10.0 & 0 & 0.0 & & \\
\hline \multirow[t]{4}{*}{ Hours of TV watching } & Do not watch & 14 & 9.3 & 24 & 16.0 & 19.054 & $<0.001^{*}$ \\
\hline & 30 minutes and less & 50 & 33.3 & 73 & 48.7 & & \\
\hline & $1-2$ hours & 79 & 52.7 & 53 & 35.3 & & \\
\hline & $>2$ hours & 7 & 4.7 & 0 & 0.0 & & \\
\hline \multirow[t]{4}{*}{ Access to gadgets } & Do not access & 48 & 32.0 & 38 & 25.3 & 8.344 & $0.04 *$ \\
\hline & $<30$ minutes & 69 & 46.0 & 72 & 48.0 & & \\
\hline & 1 hour & 28 & 18.7 & 40 & 26.7 & & \\
\hline & $>1$ hour & 5 & 3.3 & 0 & 0.0 & & \\
\hline \multirow[t]{4}{*}{ Snacking in front of TV } & Never & 30 & 20.0 & 31 & 20.7 & 63.532 & $<0.001^{*}$ \\
\hline & Occasionally & 14 & 9.3 & 48 & 32.0 & & \\
\hline & Always & 46 & 30.7 & 64 & 42.7 & & \\
\hline & Sometimes & 60 & 40.0 & 7 & 4.7 & & \\
\hline \multirow[t]{4}{*}{ Hours of study at home } & 30 minutes to 1 hour & 14 & 9.3 & 22 & 14.7 & 19.484 & $<0.001^{*}$ \\
\hline & $1-2$ hours & 69 & 46.0 & 47 & 31.3 & & \\
\hline & $2-4$ hours & 46 & 30.7 & 74 & 49.3 & & \\
\hline & $>4$ hours & 21 & 14.0 & 7 & 4.7 & & \\
\hline \multirow[t]{4}{*}{ Frequency of junk food } & Once daily & 59 & 39.3 & 6 & 4.0 & 64.988 & $<0.001^{*}$ \\
\hline & >Once daily & 34 & 22.7 & 32 & 21.3 & & \\
\hline & Once in 2 days & 23 & 15.3 & 64 & 42.7 & & \\
\hline & Once in a week & 34 & 22.7 & 48 & 32.0 & & \\
\hline \multirow[t]{4}{*}{ Soft drinks } & Never & 47 & 31.3 & 53 & 35.3 & 49.591 & $<0.001^{*}$ \\
\hline & Once in a week & 46 & 30.7 & 48 & 32.0 & & \\
\hline & Once in a month & 20 & 13.3 & 49 & 32.7 & & \\
\hline & Daily & 37 & 24.7 & 0 & 0.0 & & \\
\hline \multirow[t]{4}{*}{ Visit to dentist } & Never & 69 & 46.0 & 74 & 49.3 & 7.212 & 0.07 \\
\hline & Once in 6 months & 16 & 10.7 & 23 & 15.3 & & \\
\hline & $>6$ months & 15 & 10.0 & 22 & 14.7 & & \\
\hline & Once in a year & 50 & 33.3 & 31 & 20.7 & & \\
\hline \multirow[t]{4}{*}{ Sticking of food in teeth } & Never & 53 & 35.3 & 46 & 30.7 & 6.167 & 0.10 \\
\hline & Sometimes & 55 & 36.7 & 73 & 48.7 & & \\
\hline & Always & 40 & 26.7 & 31 & 20.7 & & \\
\hline & Others & 2 & 1.3 & 0 & 0.0 & & \\
\hline \multirow[t]{2}{*}{ Black discoloration } & Yes & 64 & 42.7 & 45 & 30.0 & 5.202 & $0.02^{*}$ \\
\hline & No & 86 & 57.3 & 105 & 70.0 & & \\
\hline & & & & & & & Contd... \\
\hline Journal of Health $\subseteq$ & ences \& Research, Volum & Issue & ary-June 20 & & & & y \\
\hline
\end{tabular}


Contd..

\begin{tabular}{|c|c|c|c|c|c|c|c|}
\hline \multirow[b]{2}{*}{ Variables } & \multirow[b]{2}{*}{ Categories } & \multicolumn{2}{|c|}{ Day scholar $(n=150)$} & \multicolumn{2}{|c|}{ Residential school $(n=150)$} & \multirow[b]{2}{*}{$\chi^{2}$ value } & \multirow[b]{2}{*}{$p$ value } \\
\hline & & $n$ & $\%$ & $n$ & $\%$ & & \\
\hline \multirow[t]{4}{*}{ Tooth pain } & Never & 52 & 34.7 & 41 & 27.3 & 23.645 & $<0.001^{*}$ \\
\hline & Once & 65 & 43.3 & 38 & 25.3 & & \\
\hline & More than once & 22 & 14.7 & 38 & 25.3 & & \\
\hline & May be & 11 & 7.3 & 33 & 22.0 & & \\
\hline \multirow[t]{4}{*}{ Tooth pain-missing school } & Never & 93 & 62.0 & 87 & 58.0 & 14.294 & $0.003^{*}$ \\
\hline & Once & 33 & 22.0 & 29 & 19.3 & & \\
\hline & More than once & 16 & 10.7 & 7 & 4.7 & & \\
\hline & May be & 8 & 5.3 & 27 & 18.0 & & \\
\hline \multirow[t]{4}{*}{ Co-curricular activity } & Sports & 53 & 35.3 & 39 & 26.0 & 5.300 & 0.15 \\
\hline & Dancing/music & 57 & 38.0 & 62 & 41.3 & & \\
\hline & Art and crafts & 12 & 8.0 & 22 & 14.7 & & \\
\hline & Indoor games & 28 & 18.7 & 27 & 18.0 & & \\
\hline \multirow[t]{4}{*}{ Sleeping time } & 8:00 PM & 25 & 16.7 & 10 & 6.7 & 8.811 & $0.03^{*}$ \\
\hline & 9:00 PM & 69 & 46.0 & 83 & 55.3 & & \\
\hline & 10:00 PM & 50 & 33.3 & 47 & 31.3 & & \\
\hline & After 10 PM & 6 & 4.0 & 10 & 6.7 & & \\
\hline
\end{tabular}

*Statistically significant

did not play during school hours as they had separate timings in the evening of play sports of their choice for 1 hour which was mandatory in all the schools.

Participation in the co-curricular activity after school was reported to be less than $40 \%$ in day scholar school children, whereas in residential school, there were compulsions on participation in activities like dance, sports, yoga, etc. regularly.

Almost $70 \%$ of day scholar school children spent $>2-3$ hours of time in studying or attending tuitions after school.

Residential schools had a curriculum of study hours for 2 hours every day after the co-curricular activities were completed.

Day scholar school children had greater access to gadgets such as mobile phones, computers, and televisions. About $75 \%$ of children reported that they spend at least 30 minutes up to 2 hours either on watching television or accessing the gadgets.

Residential school children had no access to electronic gadgets. They were allowed to watch television for 30 minutes or less per day during the free hours.

The dental experience of day school children was as follows: 60 students reported to have tooth discoloration, 90 students reported to have food lodgment sometimes or always on having food, 54 students had tooth pain at least once till date, 20 students reported to have tooth pain more than once, and around 50 students did miss school due to toothache. Fifty students reported to visit a dentist once a year, and 65 students had never visited a dentist.

In the residential school, 45 students reported to have tooth discoloration, 75 students reported to have food lodgment sometimes or always on having food, 60 students had tooth pain at least once till date, 10 students reported to have tooth pain more than once, and around 25 students did miss school due to toothache. All students reported to visit a dentist once a year since they had a routine dental check-up every year and 50 children reported to visit a dentist more than once a year.

The anthropometric data analysis concluded that in the day school, 22 children were overweight and, in a residential school, only 12 children were reported to be overweight which could be due to lesser access to junk and greater physical activity as shown in Table 1.

\section{Discussion}

This study evaluates the dental caries experience of children aged 6-10 years from two different school environments, based on their diet, physical activity, and adiposity using a dental self-report as a measure. In our study, a caries experience among children of day scholar school where the children can access to a variety of food and do not have a specific time table to spend the day and a residential school where there is a considerable time and diet constraint that is regular and monitored are being evaluated.

It has been said that diet plays an important role in the obesity epidemic. In our study, relatively more junk food was consumed by children from day scholar schools compared to residential school children including daily consumption of sugars and cakes, especially sodas. Several studies have stated that food habits and preferences are developed and established in childhood; thus, liking for, and consumption of fatty, salty, sugary, energy-dense foods in the early years could be established as a lifelong pattern. ${ }^{8}$ James et al. suggested that the consumption of carbonated drinks sweetened with sugar was a contributory factor to main causes of obesity. WHO recommended that free sugars would contribute to only $10 \%$ of daily energy intake and reducing the access to energy-dense food may help to limit the opportunities in overeating. ${ }^{9}$ This could be one of the major causes of children being less obese in a residential school as they have limited access to junk.

More than three-fourth of children from day scholar school reported to access to gadgets and television watching for 30 minutes to up to 2 hours along with snacking while watching television. Spending too much time watching television or playing electronic games together with substituting industrialized food (rich in carbohydrates/fats and poor in fiber) for processed foodstuffs are the main causes of obesity and overweight. ${ }^{8}$ William et al. suggested that television watching also correlates with in-between meal snacking, consumption of food and beverages 
that are highly advertised on television, and it requires no energy in excess of resting metabolic rates reducing the time spent on more energy-consuming activities. ${ }^{10}$

The physical activity among the day scholar and residential school children also differed in the amount of time spent in regular outdoor sports and co-curricular activities that would consume a larger amount of energy. Residential school children were engaged in physical activities such as sports, yoga, and others for at least 2-3 hours per day regularly when compared to only $60 \%$ of day scholar school children. A review on obesity in relation to physical activity by Janssen et al. states that American guidelines recommend that youth engage in 30-60 minutes of physical activity on most or all days of the week, guidelines developed in Great Britain recommend that youth engage in at least 60 minutes of daily physical activity at least 5 days a week, and Canadian guidelines recommend that all adolescents, regardless of their current activity level, gradually increase their daily physical activity participation by 90 minutes. ${ }^{11}$ Spurrier et al. suggest that physical attributes of the home environment and parental behaviors are associated with preschool children's physical activity, sedentary behavior, and dietary patterns. ${ }^{12}$

Children are considered at risk of being overweight if they are between the 85th and 95th percentile of age- and gender-related $\mathrm{BMI}$ and are considered overweight if they are at or beyond the 95th percentile of age- and gender-related BMI according to Centers for Disease Control and Prevention (CDC) guidelines. ${ }^{8}$ In our study, a greater number of day scholar children were obese and have reported to have dental caries experience when compared to the residential school children.

Several studies have been conducted linking children's dental caries experience to BMI, but the results are contradictory. In a recent systematic review, Hayden also concluded that the literature is inconclusive and that further analysis of this association and its confounding variables is needed. On the one hand, studies by Gerdin et al., Willershausen et al., Powell et al., and Yao et al. found that obesity or an unhealthily high BMI were linked to a higher number of caries lesions. On the other hand, Sheller et al. found no association between BMI and decayed-missing-filled teeth ( $\mathrm{dmft}$ ) or the number of pulp-involved teeth, whereas Benzian et al. and Bafti et al. actually found an inverse relationship, reporting an association between underweight and a higher mean $\mathrm{dmft}$, although it should be pointed out that these studies were not carried out in Western countries. ${ }^{9-12}$

Given this result, we could say that diet, physical activity, and adiposity could influence the dental caries experience among school-going children and parental attitudes toward their children's diet and oral health are significantly associated with positive parental oral health behavior.

\section{References}

1. Marshall TA, Eichenberger-Gilmore JM, et al. Dental caries and childhood obesity: roles of diet and socioeconomic status. Community Dent Oral Epidemiol 2007 Dec;35(6):449-458. DOI: 10.1111/j.1600-0528.2006.00353.x.

2. Sheiham A, James WP. Diet and dental caries: the pivotal role of free sugars reemphasized. J Dent Res 2015 Oct;94(10):1341-1347. DOI: 10.1177/0022034515590377.

3. Merchant AT, Dehghan M, et al. Diet, physical activity, and adiposity in children in poor and rich neighbourhoods: a crosssectional comparison. Nutr J 2007 Dec;6(1):1. DOI: 10.1186/14752891-6-1.

4. Gortmaker SL, Peterson K, et al. Reducing obesity via a schoolbased interdisciplinary intervention among youth: Planet Health. Arch Pediatr Adolesc Med 1999 Apr 1;153(4):409-418. DOI: 10.1001/ archpedi.153.4.409.

5. Rockett HR, Wolf AM, et al. Development and reproducibility of a food frequency questionnaire to assess diets of older children and adolescents. J Am Diet Assoc 1995 Mar 1;95(3):336-340. DOI: 10.1016/ S0002-8223(95)00086-0.

6. Janssen I, Katzmarzyk PT, et al. Health Behaviour in School-Aged Children Obesity Working Group. Comparison of overweight and obesity prevalence in school-aged youth from 34 countries and their relationships with physical activity and dietary patterns. Obes Rev 2005 May;6(2):123-132. DOI: 10.1111/j.1467-789X.2005.00176.x.

7. Fukuda $\mathrm{H}$, Ogada $\mathrm{CN}$, et al. Oral health status among 12-year-old children in a rural Kenyan community. J Dent Oral Health 2014;1:1-5. DOI: 10.17303/jdoh.2014.201.

8. Tadakamadla SK, Tadakamadla J, et al. Dental caries in relation to socio-behavioral factors of 6-year-old school children of Udaipur district, India. Dent Res J 2012 Nov;9(6):681.

9. Tripathi S, Kiran K, et al. Relationship between obesity and dental caries in children-A preliminary study. J Int Oral Health 2010 Dec 1;2(4):65-72.

10. Jong-Lenters $M$, Dommelen $P$, et al. Body mass index and dental caries in children aged 5 to 8 years attending a dental paediatric referral practice in the Netherlands. BMC Res Notes 2015 Dec;8(1):738. DOI: 10.1186/s13104-015-1715-6.

11. Hayden C, Bowler JO, et al. Obesity and dental caries in children: a systematic review and meta-analysis. Community Dent Oral Epidemil 2013 Aug;41(4):289-308. DOI: 10.1111/cdoe.12014.

12. Creske M, Modeste N, et al. How do diet and body mass index impact dental caries in Hispanic elementary school children? ADHA $2013 \mathrm{Feb}$ 1;87(1):38-46. 